\title{
Laryngeal ultrasound detects a high incidence of vocal cord paresis after aortic arch repair in neonates and young children
}

\author{
Melissa G. Y. Lee, MBBS, BMedSc, ${ }^{\text {a,b,c }}$ Johnny Millar, MBChB, PhD, ${ }^{d}$ Elizabeth Rose, MBBS, \\ Aleesha Jones, BSc, ${ }^{\mathrm{f}}$ Dora Wood, MBBS, ${ }^{\mathrm{d}}$ Taryn L. Luitingh, MD, MForSc, BSc,, a,b, \\ Diana Zannino, BSc(Hon), MSc(Research), ${ }^{\mathrm{g}}$ Johann Brink, MD, ${ }^{\mathrm{a}, \mathrm{b}}$ Igor E. Konstantinov, MD, PhD, ${ }^{\mathrm{a}, \mathrm{b}, \mathrm{c}}$ \\ Christian P. Brizard, MD, ${ }^{a, b, c}$ and Yves d'Udekem, MD, $\mathrm{PhD}^{\mathrm{a}, \mathrm{b}, \mathrm{c}}$
}

\section{ABSTRACT}

Objectives: To determine the incidence of vocal cord paresis (VCP) after neonatal aortic arch repair/Norwood-type procedure, and the effectiveness of noninvasive laryngeal ultrasound in detecting VCP compared with gold standard invasive nasoendoscopy.

Methods: Fifty-two patients who underwent an arch repair (39 of 52; 75\%) or Norwood-type procedure (13 of $52 ; 25 \%$ ) via sternotomy between April 1, 2015, and April 30, 2017 underwent laryngeal ultrasound (50 of 52; 96\%) and/ or flexible fiber optic nasoendoscopy ( 39 of $52 ; 75 \%$ ) at 48 to 72 hours after endotracheal extubation. Primary arch diagnoses were coarctation in 56\% (29 of 52), hypoplastic left heart syndrome in $17 \%$ (9 of 52), isolated hypoplastic arch in $17 \%$ (9 of 52), and interrupted aortic arch in 10\% (5 of 52). The median patient age at surgery was 5.5 days (interquartile range, 4.0-12.5 days). Fifteen patients (15 of $52 ; 29 \%$ ) required preoperative intubation.

Results: Left VCP was present in 59\% (23 of 39) of patients on nasoendoscopy and in 59\% (27 of 46) of patients on laryngeal ultrasound, and 4 additional patients had inconclusive ultrasound results. There was agreement between the results of nasoendoscopy and conclusive ultrasound in all cases. The overall sensitivity, specificity, positive and negative predictive values, and Cohen's kappa coefficient of laryngeal ultrasound compared with nasoendoscopy for the detection of left VCP were $95 \%, 88 \%, 91 \%, 93 \%$, and 0.83 , respectively. On multivariable analysis, preoperative intubation and arch repair techniques other than the Norwood procedure were associated with left VCP (odds ratio, 12.7; $P=.03$; and $14.1 ; P=.03$, respectively).

Conclusions: There is a high incidence of VCP after arch repair via sternotomy. Laryngeal ultrasound seems to be an effective and noninvasive method for detecting VCP in neonates and young children. ( $\mathrm{J}$ Thorac Cardiovasc Surg 2018;155:2579-87)

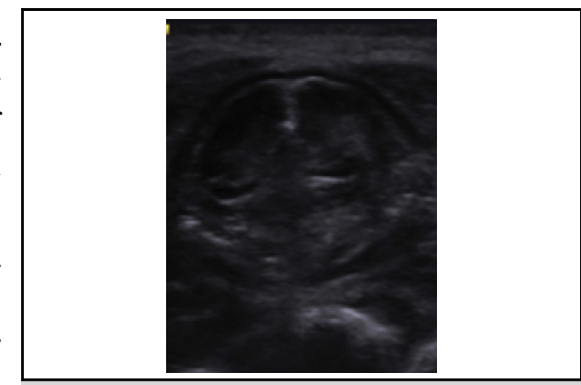

Laryngeal ultrasound image demonstrating left vocal cord paresis.

\section{Central Message}

There is a high incidence of vocal cord paresis after arch repair via sternotomy. Laryngeal ultrasound seems to be an effective and noninvasive method for detecting vocal cord paresis in neonates.

\section{Perspective}

Vocal cord paresis can occur after aortic arch repair, but its exact incidence is unknown. In this prospective study, we report a high incidence of vocal cord paresis after neonatal arch repair via sternotomy. Laryngeal ultrasound seems to be an effective and noninvasive method for detecting vocal cord paresis in neonates and young children.

See Editorial Commentary page 2588
Vocal cord paresis (VCP) from recurrent laryngeal nerve palsy is a well-known complication after neonatal aortic

\footnotetext{
From the Departments of ${ }^{\mathrm{a} C a r d i a c}$ Surgery, ${ }^{\mathrm{e}}$ Otolaryngology, and ${ }^{\mathrm{f}}$ Medical Imaging, and ${ }^{\mathrm{d}}$ Paediatric Intensive Care Unit, The Royal Children's Hospital, Melbourne, Victoria, Australia; ${ }^{\mathrm{b}} \mathrm{Heart}$ Research, and ${ }^{\mathrm{g}}$ Clinical Epidemiology and Biostatistics Unit, Murdoch Children's Research Institute, Melbourne, Victoria, Australia; and ${ }^{\mathrm{c}}$ Department of Paediatrics, University of Melbourne, Melbourne, Victoria, Australia.

This research project was supported by the Victorian Government's Operational Infrastructure Support Program. Dr Lee was supported by a National Health and Medical Research Council (NHMRC) Medical Research Postgraduate Scholarship (1134274) and an Australian Government Research Training Program Scholarship. Dr d'Udekem is a NHMRC Clinician Practitioner Fellow (1082186).
}

arch surgery that can result in significant morbidity. However, the reported incidence of vocal cord paresis

Read at the 97th Annual Meeting of The American Association for Thoracic Surgery, Boston, Massachusetts, April 29-May 3, 2017.

Received for publication May 24, 2017; revisions received Dec 9, 2017; accepted for publication Dec 24, 2017; available ahead of print March 3, 2018

Address for reprints: Yves d'Udekem, MD, PhD, Department of Cardiac Surgery, The Royal Children's Hospital, Flemington Rd, Parkville, Melbourne, Victoria 3052, Australia (E-mail: yves.dudekem@rch.org.au).

0022-5223/ $\$ 36.00$

Copyright (c) 2018 by The American Association for Thoracic Surgery

https://doi.org/10.1016/j.jtcvs.2017.12.133 


\section{Abbreviations and Acronyms \\ $\mathrm{CI}=$ confidence interval \\ $\mathrm{VCP}=$ vocal cord paresis}

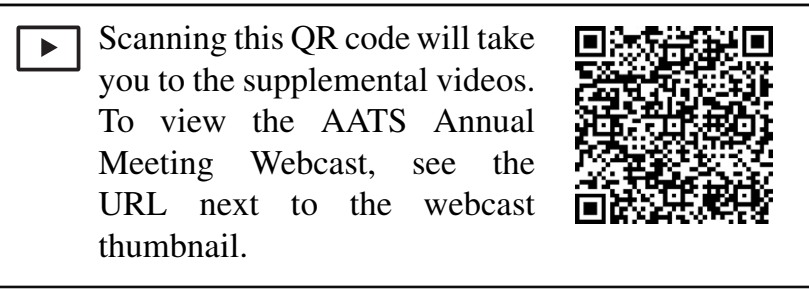

after neonatal arch surgery has varied between $9 \%$ and $59 \% .^{1-4}$

The current gold standard for the detection of VCP is the use of flexible fiber optic nasoendoscopy. Although this procedure can be performed at the bedside, it is an invasive procedure and can cause distress for neonates and young infants. Recently, noninvasive laryngeal ultrasound has been proposed for the evaluation of laryngeal and vocal cord function in children ${ }^{5-8}$; however, the use of laryngeal ultrasound has not been extensively investigated in neonates and young children after arch repair.

We performed a prospective study to determine the incidence and determinants of VCP after aortic arch repair in neonates and young children, and to determine the effectiveness of noninvasive laryngeal ultrasound in detecting VCP compared with gold standard invasive nasoendoscopy.

\section{METHODS}

\section{Study Population}

The study was approved by The Royal Children's Hospital Human Research and Ethics Committee, and written informed consent was obtained from each patient's parents. Patients who had an aortic arch lesion and underwent an arch repair or Norwood-type procedure via a sternotomy approach at The Royal Children's Hospital, Melbourne, Australia, between April 1, 2015, and April 30, 2017, were invited to participate in this study. The exclusion criterion was arch repair via a thoracotomy approach. Study consent was obtained from 55 of the 118 potential participants $(47 \%)$. However, 2 of the consented patients died before extubation and 1 missed the investigations, leaving a total of 52 patients $(44 \%)$ who participated in this study. Participants and nonparticipants were comparable in terms of age, sex ratio, and age at surgery.

Patient demographic data and cardiac anomalies are summarized in Table 1. Aortic arch lesions included coarctation of the aorta in $56 \%$ of the patients (29 of 52), isolated hypoplastic aortic arch in 17\% (9 of 52), hypoplastic left heart syndrome in 17\% (9 of 52), and interrupted aortic arch in $10 \%$ (5 of 52). Surgical procedures on the arch and concomitant cardiac procedures are listed in Table 2. Surgical repair was performed during the first year in $98 \%$ of the patients (51 of 52). Associated skeletonization of the left recurrent laryngeal nerve was routinely performed as described previously ${ }^{9}$ by 1 surgeon in 14 patients (14 of $52 ; 27 \%$ ). Intubation, extubation, and endotracheal tube characteristics
TABLE 1. Patient characeristics $(n=52)$

\begin{tabular}{|c|c|}
\hline Characteristic & Value \\
\hline \multicolumn{2}{|l|}{ Demographics } \\
\hline Male sex, n (\%) & $31(60)$ \\
\hline Median weight at surgery, kg, median (IQR) & $3.2(2.8-3.6)$ \\
\hline Median age at surgery, d, median (IQR) & $5.5(4.0-12.5)$ \\
\hline Median age at study, d, median (IQR) & $15.0(11.0-28.0)$ \\
\hline \multicolumn{2}{|l|}{ Aortic arch lesion, n (\%) } \\
\hline Coarctation of the aorta & $29(56)$ \\
\hline Isolated hypoplastic aortic arch & 9 (17) \\
\hline HLHS & $9(17)$ \\
\hline Interrupted aortic arch & $5(10)$ \\
\hline Type A & $1(2)$ \\
\hline Type B & $4(8)$ \\
\hline Any arch hypoplasia (excluding HLHS) & $34(65)$ \\
\hline \multicolumn{2}{|l|}{ Ventricular physiology, n (\%) } \\
\hline Biventricular & $40(77)$ \\
\hline Univentricular & $12(23)$ \\
\hline HLHS & $9(17)$ \\
\hline $\begin{array}{l}\text { Double inlet left ventricle }+ \text { transposition of the } \\
\text { great arteries }\end{array}$ & $2(4)$ \\
\hline Unbalanced atrioventricular septal defect & $1(2)$ \\
\hline \multicolumn{2}{|l|}{ Associated cardiac anomalies } \\
\hline Atrial septal defect/patent foramen ovale & $28(54)$ \\
\hline Ventricular septal defect & $22(42)$ \\
\hline Bicuspid/unicuspid aortic valve & $16(31)$ \\
\hline Borderline small left ventricle (excluding HLHS) & $8(15)$ \\
\hline Transposition of the great arteries & $5(10)$ \\
\hline Left superior vena cava & $5(10)$ \\
\hline Aberrant right subclavian artery & $5(10)$ \\
\hline Left ventricular outflow tract obstruction & $2(4)$ \\
\hline \multicolumn{2}{|l|}{ Noncardiac anomalies $(\mathrm{n}=14), \mathrm{n}(\%)$} \\
\hline DiGeorge syndrome & $4(8)$ \\
\hline Williams syndrome & $2(4)$ \\
\hline Other & $8(16)$ \\
\hline
\end{tabular}

$I Q R$, Interquartile range; $H L H S$, hypoplastic left heart syndrome.

are summarized in Table 3. Fifteen patients $(29 \%, 15$ of 52$)$ required at least 1 preoperative intubation, and the remaining 37 patients $(71 \%$; 37 of 52) were intubated at the time of arch repair. Seven patients $(13 \%$; 7 of 52) failed postoperative extubation and required at least 1 reintubation, for cardiac causes in 3 , for noninfective respiratory causes in 2 , and for nosocomial pneumonia and necrotizing enterocolitis in 1 patient each. Three patients $(3$ of $52 ; 6 \%$ ) required an arch reoperation before extubation, including 2 patients who underwent patch augmentation for arch reobstruction, and 1 patient who underwent a redo Damus-KayeStansel procedure for left pulmonary artery compression.

\section{Study Protocol}

The study protocol included bedside nasoendoscopy and laryngeal ultrasonography. The investigations were performed 48 to 72 hours after endotracheal extubation and before hospital discharge, to ensure clinical stability postextubation and to minimize the potential effects of edema from the endotracheal tube. The otolaryngologist and ultrasonographer were blinded to each other's reports and to patient history.

All potential participants with clinical signs of VCP were immediately referred for nasoendoscopy as part of routine clinical care regardless of their participation in this study. However, these patients' clinical nasoendoscopy results were included in this study if consent was provided. 
TABLE 2. Surgical characteristics $(\mathbf{n}=\mathbf{5 2})$

\begin{tabular}{lc}
\multicolumn{1}{c}{ Operative data } & Value \\
\hline Surgical technique, $\mathrm{n}(\%)$ & \\
End-to-side anastomosis & $30(58)$ \\
Norwood procedure & $9(17)$ \\
Patch repair & $6(12)$ \\
Damus-Kaye-Stansel + arch repair + shunt & $4(8)$ \\
Extended end-to-end anastomosis & $2(3)$ \\
End-to-side anastomosis and patch repair & $1(2)$ \\
Associated skeletonization of left recurrent laryngeal nerve & $14(27)$ \\
Associated cardiac procedures, n (\%) & \\
Atrial septal defect/patent foramen ovale closure & $17(33)$ \\
Ventricular septal defect closure & $17(33)$ \\
Blalock-Taussig shunt & $9(18)$ \\
Atrial septectomy & $8(16)$ \\
Pulmonary artery band & $3(6)$ \\
Arterial switch operation & $2(4)$ \\
Yasui procedure & $2(4)$ \\
Enlargement of pulmonary artery & $2(4)$ \\
Other & $7(15)$ \\
\hline
\end{tabular}

\section{Flexible Fiber Optic Nasoendoscopy}

Bedside flexible fiber optic nasoendoscopy was performed by a trained pediatric otolaryngologist using a validated endoscope (FNL-10 RBS; PENTAX Medical, Tokyo, Japan) without the use of sedatives. The following parameters were recorded: strength of the child's cry as unable, weak, or strong; presence of stridor; appearance of larynx; symmetry of vocal cord mobility as unilateral or bilateral, left or right; and presence of a gap between the vocal cords. Patients were routinely monitored using pulse oximetry and telemetry during the procedure.

VCP was defined as decreased or no movement in 1 or both vocal cords.

\section{Laryngeal Ultrasound}

Bedside laryngeal ultrasound was performed by a trained pediatric ultrasonographer using a standard ultrasound machine (ACUSON S2000 Ultrasound System; Siemens Medical Solutions, Malvern, Pa) paired with high-frequency linear array 14L5SP Hockey stick transducer with a thyroid examination setting (10 MHz, B-mode). The patient was positioned supine with the neck extended by placing a rolled towel under the shoulders. The ultrasound probe was placed transversely over the midline to scan the anterior neck at the level of the thyroid cartilage until the vocal cords were visualized. Images were obtained with the patient relaxed and then crying or vocalizing. Vocal cords were assessed for symmetrical abduction and adduction during breathing, swallowing saliva, and phonation. ${ }^{7,10}$ Complete adduction was confirmed on static imaging by the presence of a centrally inverted " $\mathrm{T}$ " formed by the folds of the vocal cords. Complete abduction was confirmed by the presence of a centrally inverted "V" (Figure 1, A, and Video 1).

VCP was defined as decreased or no movement in 1 or both vocal cords (Figure 1, B, and Video 2) and reported as partial or full paresis.

\section{Statistical Analysis}

All data were exported and analyzed using Stata version 13.1 (StataCorp, College Station, Tex). Data are expressed as mean \pm standard deviation or median (interquartile range) for continuous variables as appropriate. Evaluation of laryngeal ultrasound as a diagnostic test compared with gold standard nasoendoscopy was assessed by calculating sensitivity, specificity, positive and negative predictive values, and Cohen's kappa coefficient. For these diagnostic test evaluations, inconclusive ultrasounds were classified as nonnegative and nonpositive compared with
TABLE 3. ETT characteristics

\begin{tabular}{|c|c|}
\hline Characteristic & Value \\
\hline \multicolumn{2}{|l|}{ Total number of intubations, $\mathrm{n}(\%)$} \\
\hline 1 & $39(75)$ \\
\hline 2 & $10(19)$ \\
\hline 3 & $2(4)$ \\
\hline 4 & $1(2)$ \\
\hline $\begin{array}{l}\text { Intubation time from first intubation to final } \\
\text { extubation, d, median (IQR); maximum }\end{array}$ & $4.0(2.0-9.5) ; 23$ \\
\hline $\begin{array}{l}\text { Intubation time from surgery to final extubation, } \\
\text { d, median (IQR); maximum }\end{array}$ & $3.0(2.0-8.0) ; 23$ \\
\hline \multicolumn{2}{|l|}{ Preoperative } \\
\hline \multicolumn{2}{|l|}{ Number of preoperative intubations, $\mathrm{n}(\%)$} \\
\hline 0 & $37(71)$ \\
\hline 1 & $14(27)$ \\
\hline 2 & $1(2)$ \\
\hline Preoperative ETT size, mm, median (IQR) & $3.5(3.0-3.5)$ \\
\hline Cuffed preoperative ETT, n/N (\%) & $6 / 15(40)$ \\
\hline $\begin{array}{l}\text { Intubation time from preoperative intubation } \\
\text { to surgery, d, median (IQR); maximum }\end{array}$ & $2.0(1.0-4.0) ; 14$ \\
\hline \multicolumn{2}{|l|}{ Operative } \\
\hline ETT change from preoperative, $\mathrm{n} / \mathrm{N}(\%)$ & $9 / 15(60)$ \\
\hline Operative ETT size, median (IQR) & $3.0(3.0-3.5)$ \\
\hline Cuffed operative ETT, n (\%) & $32(62 \%)$ \\
\hline \multicolumn{2}{|l|}{ Postoperative } \\
\hline \multicolumn{2}{|l|}{ Number of failed extubations, n (\%) } \\
\hline 0 & $45(87)$ \\
\hline 1 & $5(10)$ \\
\hline 2 & $2(3)$ \\
\hline
\end{tabular}

$I Q R$, Interquartile range; $E T T$, endotracheal tube.

negative and positive nasoendoscopy results, respectively. Univariable analyses of risk factors for VCP were assessed using Fisher's exact test or logistic regression with all collected variables. Multivariable logistic regression was performed with all univariable variables shown to have a significant effect entered in a stepwise fashion. A $P$ value $\leq .05$ was considered statistically significant.

\section{RESULTS}

\section{Flexible Fiber Optic Nasoendoscopy}

Thirty-nine of the 52 patients ( $75 \%$ ) agreed to undergo nasoendoscopy, including 6 patients who consented for the study but consented for nasoendoscopy only if clinically indicated (Table 4). There were no complications related to nasoendoscopy in any patients. Left VCP was present in $59 \%$ of the patients ( 23 of 39 ), including 1 patient with bilateral VCP. All but 1 of the 6 patients $(83 \%)$ who consented only for inclusion of clinically indicated nasoendoscopy results had left VCP. The 1 patient who failed postoperative extubation due to nosocomial pneumonia underwent clinically indicated nasoendoscopy and had left VCP.

Assessment of the strength of cry was done in $87 \%$ of patients (34 of 39), and only $29 \%$ (10 of 34) had a strong cry. All but 1 patient $(95 \% ; 18$ of 19$)$ with left VCP had a poor cry (unable/weak). Patients with a poor cry (unable/weak) 

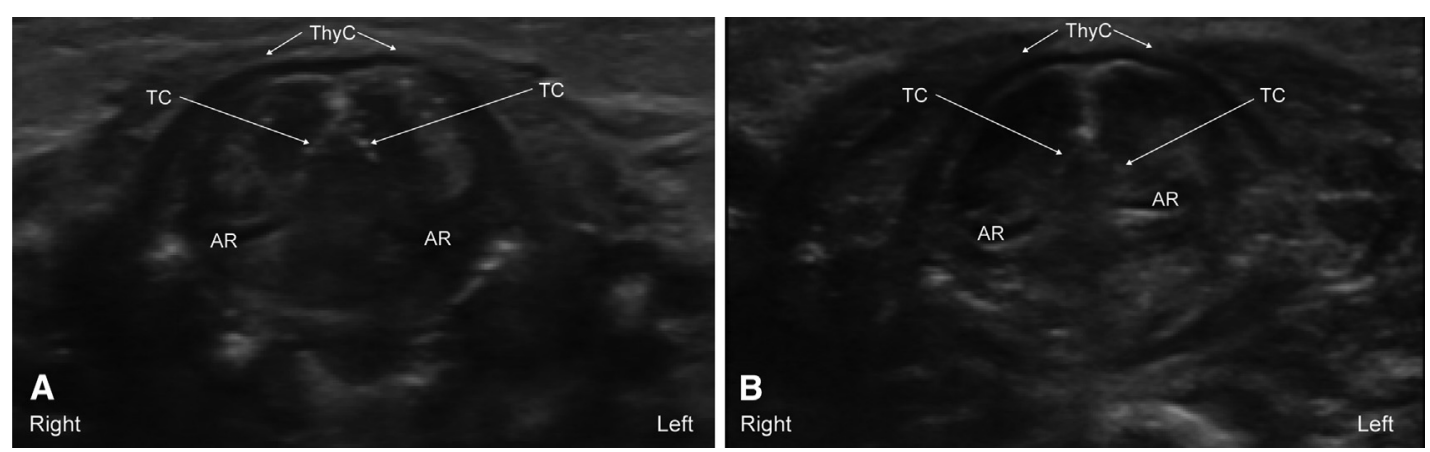

FIGURE 1. Laryngeal ultrasound images. A, Normal vocal cord function demonstrating symmetrical abduction with the presence of a centrally inverted V. B, Left vocal cord paresis demonstrating asymmetrical abduction. $A R$, Arytenoid cartilage; $T C$, true vocal cord; Thy , thyroid cartilage.

were more likely than patients with a strong cry to have left VCP $(75 \%$ [18 of 24$]$ vs $10 \%$ [ 1 of 10 ]; $P=.001)$.

Laryngeal edema was present in $24 \%$ of the patients ( 8 of $33)$, and all but 1 of these patients $(88 \% ; 7$ of 8$)$ had left VCP. There was no difference in the rate of laryngeal edema between patients with left VCP and those without (37\% [7 of 19 ] vs $7 \%$ [1 of 14]; $P=.10$ ).

A gap between the vocal cords was present in $71 \%$ of patients ( 20 of 28). There was no difference in the rate of VCP between patients with a gap and those without (65\% [13 of 20 ] vs $38 \%$ [ 3 of 8 ]; $P=.20$ ).

\section{Laryngeal Ultrasound}

Fifty of the 52 patients $(96 \%)$ underwent laryngeal ultrasound, and 2 were missed due to logistical issues (Table 4). Four patients ( 4 of $52 ; 8 \%$ ) had an inconclusive ultrasound result, due to poor image quality in 3 patients and to poor cooperation in 1 patient, leaving 46 conclusive ultrasounds for analysis. Left VCP was present in $59 \%$ of patients ( 27 of 46), including 1 patient with bilateral VCP. The degree of immobility was partial paresis in 19\% (5 of 27) and paralysis in $81 \%$ (22 of 27$)$.

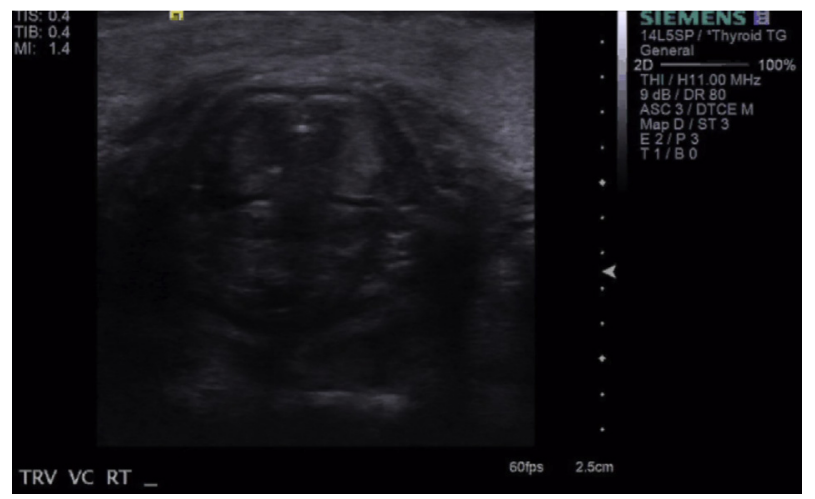

VIDEO 1. Normal vocal cord function demonstrating symmetrical adduction with the presence of a centrally inverted $\mathrm{T}$, and symmetrical abduction with the presence of a centrally inverted V. Video available at: http://www.jtcvsonline.org/article/S0022-5223(18)30306-4/fulltext.
Three of the 4 patients with an inconclusive ultrasound underwent nasoendoscopy, and only 1 patient had left $\operatorname{VCP}(1$ of $3 ; 33 \%)$.

\section{Agreement Between Nasoendoscopy and Laryngeal Ultrasound}

Thirty-seven of the 52 patients $(71 \%)$ underwent both nasoendoscopy and laryngeal ultrasound (Table 5). There was agreement between the results of nasoendoscopy and laryngeal ultrasound in all 34 cases with conclusive ultrasounds. The overall sensitivity, specificity, positive and negative predictive values, and Cohen's kappa coefficient of laryngeal ultrasound compared with gold standard nasoendoscopy for VCP were $95 \%, 88 \%, 91 \%, 93 \%$, and 0.83 , respectively $(95 \%$ confidence interval [CI], 76\%$99.9 \%, 62 \%-98 \%, 73 \%-97 \%, 67 \%-99 \%$, and $0.65-1.0$, respectively).

\section{Determinants of Left VCP}

There were no significant differences in sex, noncardiac anomalies, age at surgery, or weight at surgery between patients with left VCP on laryngeal ultrasound and those without left $\operatorname{VCP}(P=.90, .30, .50$, and .30 , respectively $)$

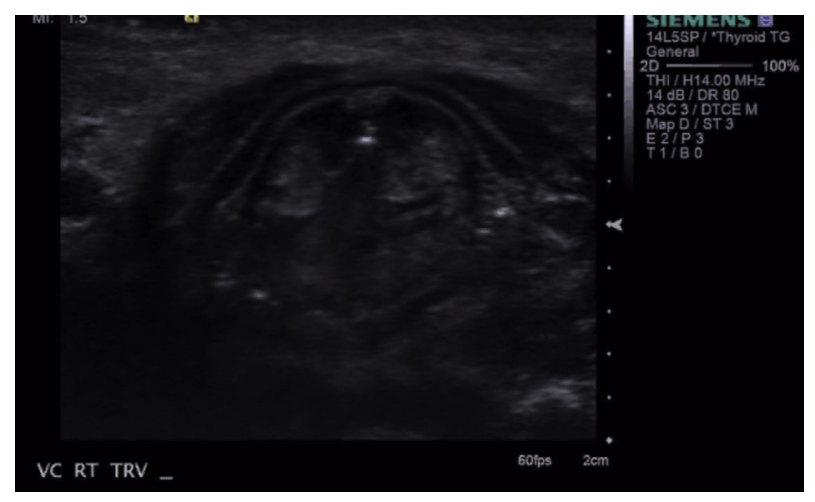

VIDEO 2. Left vocal cord paresis on laryngeal ultrasound demonstrating asymmetrical adduction and abduction. Video available at: http://www.jtcvsonline.org/article/S0022-5223(18)30306-4/fulltext. 
TABLE 4. Results of nasoendoscopy and laryngeal ultrasound

\begin{tabular}{|c|c|c|c|c|}
\hline Variable & Total $(\mathbf{n}=\mathbf{5 2})$ & No VCP & Left VCP & $P$ value, no VCP vs VCP \\
\hline Nasoendoscopy, $\mathrm{n}$ & $39 *$ & 16 & 22 & \\
\hline Strength of cry, n (\%) & 34 & 15 & 19 & \\
\hline Poor cry & $24(71)$ & $6(40)$ & $18(95)$ & .001 \\
\hline Unable & $2(6)$ & $2(13)$ & $0(0)$ & \\
\hline Weak & $22(65)$ & $4(27)$ & $18(95)$ & \\
\hline Strong cry & $10(29)$ & $9(60)$ & $1(5)$ & \\
\hline \multicolumn{5}{|l|}{ Appearance, $\mathrm{n} / \mathrm{N}(\%)$} \\
\hline Laryngeal edema & $8 / 33(24)$ & $1 / 14(7)$ & $7 / 19(37)$ & .10 \\
\hline Gap between vocal cords & $20 / 28(71)$ & $7 / 12(5)$ & $13 / 16(81)$ & .20 \\
\hline Laryngeal ultrasound, $\mathrm{n}$ & $50 \dagger$ & 19 & 27 & \\
\hline \multicolumn{5}{|c|}{ Asymmetrical movement of left vocal cord } \\
\hline On breathing, n (\%) & $27(53)$ & $0(0)$ & $27(100)$ & $<.0001$ \\
\hline On crying, n/N (\%) & $24 / 45(53)$ & $0(0)$ & $24 / 26(92)$ & $<.0001$ \\
\hline
\end{tabular}

$V C P$, Vocal cord paresis. *Thirteen patients did not consent to nasoendoscopy. $†$ Two patients did not complete laryngeal ultrasound due to logistical issues, and 4 had an inconclusive result.

(Table 6). All 5 patients $(100 \%)$ with an interrupted aortic arch had left VCP $(P=.07)$. There was no difference in the rate of left VCP on laryngeal ultrasound between patients who underwent skeletonization of the left recurrent laryngeal nerve and those who did not (64\% [9 of 14] vs $56 \%$ [18 of 32]; $P=.70$ ).

On multivariable analysis, preoperative intubation and undergoing arch repair via a technique other than the Norwood procedure was associated with left VCP on laryngeal ultrasound (odds ratio, 12.7; 95\% CI, 1.35-119; $P=.03$ and 14.1; 95\% CI, 1.30-153; $P=.03$, respectively) (Table 6).

Even after excluding the 15 patients who underwent preoperative intubation, patients who underwent non-Norwood repairs were more likely to have left VCP on laryngeal ultrasound (57\% [16 of 28$]$ vs $0 \%$ [0 of 5]; $P=.04)$.

\section{DISCUSSION}

As demonstrated by our findings, VCP may be a complication for more than one-half of neonates and young children undergoing aortic arch or Norwood-type repair via sternotomy. This finding is of great concern as VCP can result in significant morbidity.

VCP and recurrent laryngeal nerve palsy after cardiac surgery are often attributed to an iatrogenic cause, such as compression of the vocal cords from endotracheal intubation or directly from surgery. In this large prospective cohort of 52 patients who underwent arch repair or Norwood-type procedure via sternotomy, we demonstrated preoperative endotracheal intubation and arch repair techniques other than the Norwood procedure to be independently associated with left VCP. The VCP was left-sided in all but 1 of our patients, supporting nerve injury from surgery rather than from endotracheal intubation as the likely cause. More than one-half of the patients had left VCP after non-Norwood repairs, even after the exclusion of patients requiring preoperative intubation. This higher rate of VCP may be attributed to recurrent laryngeal nerve damage arising from more extensive dissection or anterior displacement of the upper descending thoracic aorta in the end-to-side anastomosis technique, which was performed in more than two-thirds of those who did not undergo a Norwood procedure. Interestingly, we previously performed a retrospective review of our outcomes after end-to-side anastomosis repair for biventricular aortic arch lesions and reported only a $14 \%$ incidence of left $\mathrm{VCP},{ }^{11}$ likely a gross underestimation of the true incidence. We previously described a technique of skeletonization of the left recurrent laryngeal nerve to preserve its function during arch repair and Norwoodtype procedures. ${ }^{9}$ Although we did not demonstrate any improvement in the rate of VCP with the use of this technique, this may have been related to nerve injury from undue retraction or suction rather than from direct transection. Care should be taken to preserve and minimize undue damage to the nerve. We previously hypothesized that recovery of left VCP would be accelerated after the

TABLE 5. Comparison of laryngeal ultrasound and gold standard nasoendoscopy

\begin{tabular}{|c|c|c|c|c|}
\hline \multirow[b]{2}{*}{ Laryngeal ultrasound } & \multicolumn{2}{|c|}{ Nasoendoscopy, n (\%) } & \multirow[b]{2}{*}{ Sensitivity, $\%$} & \multirow[b]{2}{*}{ Specificity, \% } \\
\hline & $\overline{\operatorname{No} V C P}(n=16)$ & Left VCP $(n=21)$ & & \\
\hline No $\operatorname{VCP}(\mathrm{n}=15)$ & $14(88 \%)$ & $1(5 \%)^{*}$ & & \\
\hline Left VCP $(n=22)$ & $2(12 \%)^{*}$ & $20(95 \%)$ & $95 \%$ & $88 \%$ \\
\hline
\end{tabular}

$V C P$, Vocal cord paresis. *Total group $(\mathrm{n}=37)$ includes 3 patients with inconclusive laryngeal ultrasound. 
TABLE 6. Univariable logistic regressions and the final multivariable logistic model describing factors associated with left vocal cord paresis on laryngeal ultrasound

\begin{tabular}{|c|c|c|c|c|}
\hline \multirow[b]{2}{*}{ Variable } & \multicolumn{2}{|c|}{ Univariable analysis } & \multicolumn{2}{|c|}{ Multivariable analysis } \\
\hline & OR $(95 \%$ CI $)$ & $P$ value & $\overline{\text { OR }(95 \% \text { CI })}$ & $P$ value \\
\hline Male sex & $0.91(0.28-2.98)$ & .90 & & \\
\hline Age at surgery (d) & $1.00(1.00-1.01)$ & .50 & & \\
\hline Weight at surgery $(\mathrm{kg})$ & $1.27(0.78-2.06)$ & .30 & & \\
\hline Noncardiac anomaly & $2.25(0.51-9.91)$ & .30 & & \\
\hline \multicolumn{5}{|l|}{ Aortic arch lesion } \\
\hline Coarctation of the aorta & $1.31(0.40-4.27)$ & .70 & & \\
\hline Interrupted aortic arch & $*$ & & & \\
\hline HLHS & $0.17(0.03-0.98)$ & .05 & $\dagger$ & \\
\hline Any arch hypoplasia (excluding HLHS) & $1.17(0.34-3.99)$ & .80 & & \\
\hline \multicolumn{5}{|l|}{ Ventricular physiology } \\
\hline Biventricular & 1.00 & & & \\
\hline Univentricular & $0.30(0.07-1.22)$ & .09 & & \\
\hline \multicolumn{5}{|l|}{ Intubation characteristics } \\
\hline Total intubation time (d) & $0.97(0.88-1.07)$ & .60 & & \\
\hline More than 1 intubation & $0.63(0.16-2.51)$ & .50 & & \\
\hline Preoperative intubation & $5.84(1.12-30.6)$ & .04 & $12.7(1.35-119)$ & .03 \\
\hline Mean operative ETT size (mm) & $1.45(0.22-9.50)$ & .70 & & \\
\hline Operative ETT cuffing & $1.24(0.37-4.10)$ & .50 & & \\
\hline \multicolumn{5}{|l|}{ Surgical characteristics } \\
\hline \multicolumn{5}{|l|}{ Norwood procedure } \\
\hline Norwood procedure & 1.00 & & & \\
\hline Other techniques & $5.77(1.02-32.7)$ & .05 & $14.1(1.28-153)$ & .03 \\
\hline \multicolumn{5}{|l|}{ Other techniques } \\
\hline End-to-side anastomosis & $2.22(0.67-7.41)$ & .20 & & \\
\hline Damus-Kaye-Stansel + arch repair + shunt & $2.25(0.22-23.5)$ & .50 & & \\
\hline Patch repair & $1.07(0.16-7.06)$ & 1.0 & & \\
\hline Skeletonization of left recurrent laryngeal nerve & $1.40(0.38-5.12)$ & 60 & & \\
\hline Cardiopulmonary bypass time (min) & $1.00(0.99-1.01)$ & .50 & & \\
\hline Aortic cross-clamp time, (min) & $0.99(0.98-1.00)$ & .20 & & \\
\hline Arch reoperation & $0.69(0.04-11.8)$ & .80 & & \\
\hline
\end{tabular}

The model includes 46 patients; $P=.002, R^{2}=0.20 . O R$, Odds ratio; $C I$, confidence interval; HLHS, hypoplastic left heart syndrome; ETT, endotracheal tube. *Unable to be calculated as all 5 patients had left vocal cord paresis. $†$ Not included in multivariable model due to collinearity with Norwood procedure.

skeletonization technique, ${ }^{9}$ but further follow-up is required.

We were astonished to see complete agreement between the results of nasoendoscopy and conclusive laryngeal ultrasound and substantial agreement even after the inclusion of inconclusive ultrasounds. We demonstrated an overall $95 \%$ sensitivity and $88 \%$ specificity for laryngeal ultrasound compared with the current gold standard nasoendoscopy. Our results are similar to those reported in a recent study by Ongkasuwan and colleagues ${ }^{8}$ of 46 patients who underwent pediatric cardiac surgery and reported $84 \%$ sensitivity and $95 \%$ specificity for the detection of VCP using laryngeal ultrasound compared with nasoendoscopy. However, that study did not include a homogenous cohort of neonatal arch repairs and included different types of pediatric cardiac surgeries. Nonetheless, laryngeal ultrasound is not without limitations, as we found in the 4 patients with inconclusive ultrasound results due to the poor quality of images obtained or lack of patient cooperation.

In our center, we have not routinely screened all patients for VCP after aortic arch or Norwood-type repair via sternotomy. It was concerning to note the presence of left VCP in all but 1 of the 6 patients who consented only for inclusion of clinically indicated nasoendoscopy results, such as in aspiration pneumonia. Although clinical assessment of the strength of cry during nasoendoscopy revealed left VCP in $75 \%$ of patients with a a poor cry, there were false-positive and false-negative results. Accurate assessment of vocal cord function should include postoperative bedside imaging for all patients and should not rely on clinical symptoms alone. We are now advocating that all neonates and young children undergoing aortic arch or 
Norwood-type repair via sternotomy be referred for bedside vocal cord assessment using laryngeal ultrasound, and that patients with inconclusive results be referred for nasoendoscopy. All of the patients in our study with VCP were immediately referred to a speech pathologist for further evaluation and follow-up.

Although all laryngeal ultrasounds in the present study were performed by trained pediatric ultrasonographers, we believe that laryngeal ultrasound is a reasonably straightforward technique that clinicians with previous ultrasound experience can be trained to perform independently at the bedside. Laryngeal ultrasound will likely become a useful tool in the pediatric intensivist's armamentarium.

\section{Limitations}

We were unable to obtain consent from the parents of all potential participants, particularly for invasive nasoendoscopy, and thus our reported incidence of VCP might not be accurate. Moreover, we had some missing data in our nasoendoscopy assessment, and so the incidence of poor cry, laryngeal edema, and gap between the vocal cords might not be accurate. It is difficult to differentiate the impact of endotracheal intubation and arch surgery on vocal cord paresis, because we did not have a control group of nonarch repairs in our study. Although we did not perform preoperative assessment of vocal cord function in our patients, it has been reported that routine preoperative vocal cord function evaluation in the absence of previous arch intervention or genetic syndrome is unlikely to be abnormal. ${ }^{3}$ This study was not designed to study the impact of VCP on nutrition. We did not evaluate vocal cord function at follow-up in this study, but it has been demonstrated that VCP after arch repair or a Norwood-type procedure is likely to persist even after 1 year of follow-up.

\section{CONCLUSIONS}

There is a high incidence of VCP after aortic arch repair via sternotomy. Laryngeal ultrasound seems to be an effective and noninvasive method for detecting VCP in neonates and young children.

\section{Webcast}

You can watch a Webcast of this AATS meeting presentation by going to: https://aats.blob.core.windows.net/ media/17AM/2017-05-02/RM312/05-02-17_Room312_ 1631_Lee.mp4.

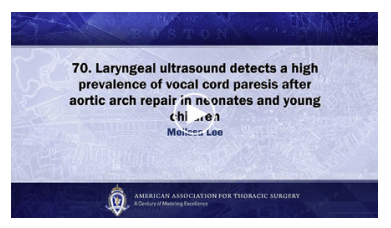

\section{Conflict of Interest Statement}

Dr Brizard is a consultant for Admedus. Dr d'Udekem is a consultant for Actelion and MSD. All other authors have nothing to disclose with regard to commercial support.

We acknowledge the assistance of Cain Brockley and Sara Kernick in the Department of Medical Imaging at The Royal Children's Hospital.

\section{References}

1. Skinner ML, Halstead LA, Rubinstein CS, Atz AM, Andrews D, Bradley SM Laryngopharyngeal dysfunction after the Norwood procedure. J Thorac Cardiovasc Surg. 2005;130:1293-301.

2. Averin K, Uzark K, Beekman RH III, Willging JP, Pratt J, Manning PB. Postoperative assessment of laryngopharyngeal dysfunction in neonates after Norwood operation. Ann Thorac Surg. 2012;94:1257-61.

3. Davies RR, Carver SW, Schmidt R, Keskeny H, Hoch J, Pizarro C. Laryngopharyngeal dysfunction independent of vocal fold palsy in infants after aortic arch interventions. J Thorac Cardiovasc Surg. 2014;148:617-24.e2.

4. Pham V, Connelly D, Wei JL, Sykes KJ, O'Brien J. Vocal cord paralysis and dysphagia after aortic arch reconstruction and Norwood procedure. Otolaryngol Head Neck Surg. 2014;150:827-33.

5. Vats A, Worley GA, de Bruyn R, Porter H, Albert DM, Bailey CM. Laryngeal ultrasound to assess vocal fold paralysis in children. J Laryngol Otol. 2004;118:429-31.

6. Shaath GA, Jijeh A, Alkurdi A, Ismail S, Elbarbary M, Kabbani MS. Ultrasonography assessment of vocal cords mobility in children after cardiac surgery. $J$ Saudi Heart Assoc. 2012;24:187-90.

7. Jadcherla SR, Gupta A, Stoner E, Coley BD, Wiet GJ, Shaker R. Correlation of glottal closure using concurrent ultrasonography and nasolaryngoscopy in children: a novel approach to evaluate glottal status. Dysphagia. 2006;21:75-81.

8. Ongkasuwan J, Ocampo E, Tran B. Laryngeal ultrasound and vocal fold movement in the pediatric cardiovascular intensive care unit. Laryngoscope. 2017; $127: 167-72$

9. Sughimoto K, Pratap H, Konstantinov IE, Brizard CP, d'Udekem Y. Skeletonization of the recurrent laryngeal nerve during Norwood procedure and aortic arch repair. Ann Thorac Surg. 2015;100:1473-5.

10. Wong KP, Woo JW, Youn YK, Chow FC, Lee KE, Lang BH. The importance of sonographic landmarks by transcutaneous laryngeal ultrasonography in postthyroidectomy vocal cord assessment. Surgery. 2014;156:1590-6; discussion 1596.

11. Lee MG, Brink J, Galati JC, Rakhra SS, Konstantinov IE, Cheung MM, et al. End-to-side repair for aortic arch lesions offers excellent chances to reach adulthood without reoperation. Ann Thorac Surg. 2014;98:1405-11.

Key Words: aortic arch, coarctation of the aorta, laryngeal ultrasound, nasoendoscopy, Norwood procedure, pediatric cardiac surgery, vocal cord paresis

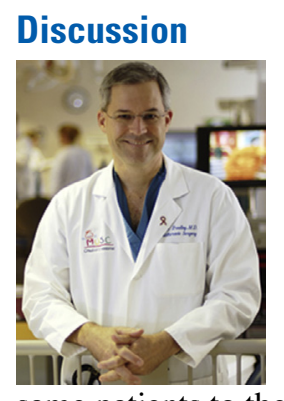

Dr S. Bradley (Charleston, SC). You have made a very nice presentation of the use of a noninvasive ultrasound technique for evaluating vocal cord function following aortic surgery in neonates. I want to first of all commend you for not just presenting your approach, but also comparing it in the same patients to the gold standard, endoscopic examination. This comparison is a real strength of your presentation. You showed an exact correlation with endoscopy, and I think your findings are quite convincing. While endoscopy is fairly 
benign, I do think that your approach is likely to be better tolerated by the patients.

A potential limitation of your study is that you evaluated just under half of your potential participants, although I doubt that this significantly affected your findings. I also definitely agree with your point that physical exam by itself suggests vocal cord function, but it is incomplete and has both false-positives and false-negatives. So any truly accurate assessment of the rate of recurrent nerve injury requires either endoscopy in all patients or potentially your approach.

You have demonstrated a fairly high incidence of vocal cord dysfunction in your patients, almost $60 \%$. For the purposes of comparison, our group has undertaken routine postoperative endoscopy in all of our neonates undergoing aortic arch reconstruction since 2003. Over that period, about two-thirds of these patients had a Norwood procedure and about one-third had a biventricular repair carried out through a sternotomy. Among those patients, the Norwood patients had a vocal cord paresis rate of $16 \%$, and the arch repairs from the front had a little bit higher incidence, $22 \%$. So clearly these rates can be fairly variable, and I think probably highlight the importance of surgical technique. This generally means avoiding cautery in the area of the nerve and limiting stretch of the nerve as much as possible. On Saturday, Jim Tweddell also mentioned the approach of using bipolar cautery.

So my first question for you is, have your findings led to any discussions or changes by your surgical group aimed at recurrent nerve protection?

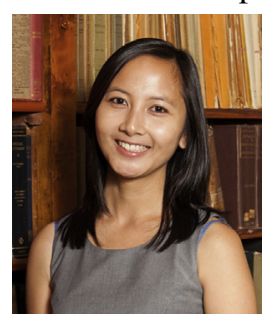

Dr Lee. Thank you for your question. We recently described a technique to preserve the left recurrent laryngeal nerve which was published in the Annals of Thoracic Surgery in 2015. We described the technique of skeletonization of the left recurrent laryngeal nerve using bipolar cautery and deliberate placement of the nerve posterior to the reconstructed arch.

At that time, there were 12 patients who underwent this skeletonization and only the first 2 patients underwent laryngoscopy, and they were both found to have normal vocal cord function. The subsequent patients at that time were thought to have no vocal cord paresis based on clinical picture.

One surgeon currently performs this technique. In our series, after excluding the patients who underwent preoperative intubations, which can be a confounding factor, this surgeon performed 9 of the skeletonization procedures, and 4 of them (44\%) had left vocal cord paresis.

I do acknowledge that it is difficult to determine the exact impact of this particular skeletonization. As you have mentioned, there are other reasons during surgery that may cause vocal card paresis, such as stretch injury or suction injury. At the time of we published our technique, we hypothesized that this particular skeletonization and deliberate posterior placement of the nerve may result in improvement or at least recovery of vocal cord paresis later on in life. So we are currently in the process of performing a follow-up study to determine if the left vocal cord paresis does recover and in particular, whether this surgeon and his skeletonized patients have a better improvement rate.

Dr Bradley. I did want to ask you about that. So, just to clarify, how many patients have had recurrent nerve skeletonization and relocation and have also had laryngeal ultrasound?

Dr Lee. In total, there were 14 patients who underwent associated skeletonization of the laryngeal nerve. In the particular analysis I quoted, I excluded patients who had preoperative intubation, as this was found to be an independent risk factor for vocal paresis, and this left 9 patients that the surgeon operated on who did not require preoperative intubation. Of those 9, 4 had vocal cord paresis on laryngeal ultrasound.

Dr Bradley. Okay, so a rate of about 44\%. I also believe that the preoperative intubation is a red herring. Essentially all of your pareses-and this is similar to ours as wellwere on the left side, which really goes along with surgical injury rather than preoperative intubation as the cause.

Can you tell us a little bit about how easy it is to use laryngeal ultrasound? Who carries out the studies, what training is involved, and how difficult will it be for the rest of us to adopt?

Dr Lee. In our study, we had very 2 very proficient pediatric ultrasonographers perform our laryngeal ultrasounds, who learned this technique from their experience in pediatric thyroid surgery patients. However, laryngeal ultrasound is currently being rolled out in our pediatric intensive care unit. in fact, we are teaching our PICU fellows how to perform this procedure so that they can perform it at the patient's beside and refer to speech pathology for further management of vocal paresis if detected. We can do it at the bedside, and it doesn't have to be done downstairs in radiology.

Dr Bradley. Your data showed that a portion of your patients had what you called paresis, and the remainder had paralysis. It has been my assumption, based on really no solid data, that the paretic patients are more likely to recover over time. Do you have follow-up information from ultrasounds in any of your patients to tell us what their recovery rates are like?

Dr Lee. As I alluded to before, we are conducting a follow-up study to determine the recovery of the vocal cord paresis. We are currently in the midst of doing this study. So far, I have recruited 9 patients to come back and do the follow-up study. Of the 9, 4 of them had left vocal cord paresis postoperatively, and unfortunately so far after roughly a mean of 12 months of follow-up, all 4 of them still have left vocal cord paresis. So it will be interesting to see with more patients whether or not the left vocal cord paresis 
recovers, although at this stage it looks like it has not recovered by 12 months.

Dr Bradley. That has been our finding as well. In followup, somewhere around $70 \%$ of these are permanent.

I think this is a really useful contribution. Thank you very much for presenting it to us.

Dr Lee. Thank you very much, Professor Bradley.

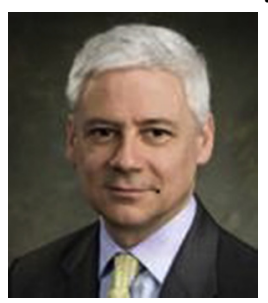

Dr C. Pizarro (Wilmington, Del). That was a beautiful presentation and a very innovative approach to this really not so trivial issue. Following $\mathrm{Dr}$ Bradley's initiative and initial paper published in 2003, we actually presented at this very same meeting our experience with over 100 patients who have been evaluated. And I just wanted to ask you, besides the ultrasound assessment, are you actually doing any other form of evaluation after this, I mean, oropharyngeal evaluation, barium swallow, or anything else? Because what we found was that even though we all tend to believe that left vocal cord paresis was really the major issue, it seems like there is a substantial number of patients in whom the vocal cord actually could be normal and yet those patients would have massive silent aspiration because they would have a sensory issue related to the larynx

So could you tell us a little bit about what other form of evaluation do you do, and how many of these patients actually ended up being discharged home treated orally as you would have expected, and in particular those who have single-ventricle palliation?

Dr Lee. Thank you for your question. In our institution, we have not routinely screened patients for vocal cord paresis after an aortic arch repair or Norwood type procedure. Based on the results of this study, we are routinely doing that now, with the bedside laryngeal ultrasound as first-line screening.

It is difficult to determine exactly what clinical impact this had, as we performed these studies so early after extubation that if patients did have clinical signs, we picked them up so quickly that they then were referred to speech pathology for appropriate management.

We are particularly interested in, as you mentioned, the sort of clinical sequelae of this paresis. In our follow-up study, we also are examining the clinical implications of left vocal cord paresis over that first 12-month postoperative period, such as whether the patient had any feeding or swallowing issues or any admissions for aspiration pneumonia. I hope that I will be able to present these data in the near future.

I do not know at this stage whether or not the patients were discharged home with oral feeds.

Dr Pizarro. Well, it looks like you are going to have a lot more to tell us in the future. Thank you.

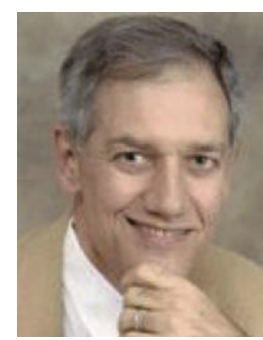

Dr R. Jonas (Wash, DC). A very nice presentation. This looks like a really interesting technique. I am wondering, can you use this to look at the coordination of the pharynx as well as the larynx, because one of the most common problems we have with babies postoperatively is with delayed feeding and having to stay in the hospital because of poor coordination of swallowing. So can you use this to assess more than just the vocal cords

Dr Lee. That's a good question. I'm not familiar with the use of ultrasound for pediatric pharyngeal assessment, although I know it can be performed in adults. However, from attending quite a few of these laryngeal ultrasound sessions, I have observed that it can be quite difficult to coordinate swallowing with ultrasound assessment simultaneously in this young age group. It is quite difficult to perform laryngeal ultrasound in some babies because of how uncooperative they can be. I would be interested to find out more from our ultrasonographers.

Dr Jonas. The reason that I think it's important for us to use this technique is because I would like to suggest that you should be doing this exam preoperatively as well as postoperatively. The reason I say that is there is now a mouse model of DiGeorge syndrome, and one of the interesting findings is that the development of the vagus nerve and the glossopharyngeal nerve is markedly abnormal in this model. So I am suspicious that some of the swallowing problems that we see postoperatively and perhaps some of these laryngeal problems that you are seeing may in fact be developmental and may be related to the development of the ninth and tenth cranial nerve.

Have you done any preoperative studies?

Dr Lee. No, at this stage we have not performed any preoperative studies.

Dr Jonas. This may be like the MRI story, where we saw a very high incidence of brain injury that we attributed to surgery until we started doing preoperative MRIs and found a lot of newborns already had a lot of structural injury in their brain. But I think there are a lot of great possibilities here. Thank you.

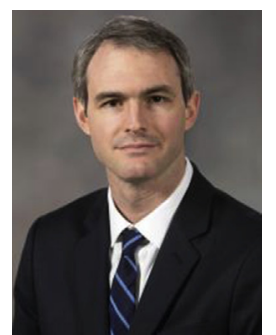

Dr C. Greenleaf (Jackson, Miss). Thank you for your interesting presentation. I have a question. Were the people who read the ultrasound blinded to the outcomes of the endoscopic study? Dr Lee. Yes, absolutely. The ultrasonographer and otolaryngologist were blinded to both each other's reports and to patient histories. They did not know exactly what type of arch repair they had received, but they just knew that they had received an arch surgery via sternotomy.

Dr Greenleaf. But the people who read it didn't know what the endoscopic findings were?

Dr Lee. No, they did not know each other's findings. 